\title{
Rapid fabrication of ultra-smooth Y-TZP bioceramic surfaces by dual-axis wheel polishing: process development and tribological characterization
}

\author{
Ange Lu ${ }^{\mathrm{a}}$, Zhentao Shang ${ }^{\mathrm{a} *}, \mathrm{Xichun} \mathrm{Luo}^{\mathrm{b}}$, Tan $\mathrm{Jin}^{\mathrm{a}}, \mathrm{Hu} \mathrm{Luo}^{\mathrm{a}}$ \\ ${ }^{a}$ National Engineering Research Centre for High Efficiency Grinding, Hunan \\ University, Changsha, Hunan 410082, China \\ ${ }^{b}$ Ultra Precision Manufacturing Department of Design, Manufacture and \\ Engineering Management, University of Strathclyde, Glasgow, G1 1XQ, UK
}

*Corresponding author

E-mail address: angelu_hnu@163.com (A. Lu)

huda_szt2005@sina.com (Z. Shang) 


\section{Abstract:}

The existing artificial joint implants using bioceramic materials face problems of difficulty in manufacturing and premature failure due to wear. This paper investigated a rapid preparing process of ultra-smooth surfaces of yttria-stabilized tetragonal zirconia polycrystal bioceramics based on the dual-axis wheel polishing (DAWP) system. Friction and wear tests were conducted to prove that the prepared ultra-smooth surface can effectively reduce wear. The effects of process parameters on polishing performances were investigated. The XRD and SEM analysis and micro-hardness testing were used to characterize the prepared surface in material behaviors. Tribological tests were carried out on a ball-on-plate reciprocating tribometer to comparatively study the tribological behavior and wear mechanism of the prepared ultra-smooth surfaces and the conventional surface at sub-microscale. The used finishing technology can steadily achieve fast preparation of ultra-smooth bioceramic surfaces, and with a high material removal rate (the highest value was $1.14 \mathrm{mg} / \mathrm{min}$ ). Besides, in contrast to the conventional surface (Ra $129 \mathrm{~nm}$ ), the prepared ultra-smooth surface $(\mathrm{Ra} 0.38 \mathrm{~nm})$ achieved a much smaller friction coefficient, and much less wear volume, indicating that the wear resistance of the ultra-smooth surface was significantly improved.

Keywords: Y-TZP bioceramics; ultra-smooth surface; polishing; friction and wear behavior 


\section{Introduction}

Artificial joint replacement (e.g., Total Hip Replacement, Total Knee Replacement, etc.) is the most effective method for the treatment of intermediate and late (advanced) orthopedic diseases (e.g., arthrophlogosis, osteonecrosis, etc.) [1, 2]. It is used to replace patients' diseased bones, restore their mobility, improve their quality of life and longevity $[3,4]$. Hitherto, it has been widely applied worldwide, and as the population ages, the demand on performing replacement surgery is gradually growing [5-7]. As an ideal implant material, bioceramic has been used to manufacture a variety of joint implant devices in recent decades [6, 8-11]. It possesses high hardness and wettability [12], and can effectively avoid the problems of increased blood metal ion concentration and cytotoxicity caused by metal implants, and poor wear resistance of polymer implant materials. Among bioceramic materials, zirconia ceramics have higher fracture toughness and bending strength and better biocompatibility, and show a lower risk of implant fracture [13-18]. Thus, they have received great interest in the field of medical implants.

Aseptic loosening is one of the major modes of premature failure encountered by the existing joint implants, and for this reason, patients often need to undergo high-risk revision surgery $[19,20]$. Submicron-micron scale wear debris generated from the wear process of the articular bearing surface react with the surrounding body tissue and cause osteolysis, leading to the aseptic loosening [21-23]. Therefore, reducing wear of the bearing surface is the key issue for improving the lifespan and service performance of the implants. At present, researches on methods of friction and wear improvement 
mainly focus on new implant materials development and modification, surface coating and microstructure preparation [24-28]. In addition, it is worth noting that some studies have shown that to improve surface quality (i.e., improving surface smoothness and reducing surface roughness) is also an effective way to reduce ceramic material wear. Preis et al. reported their friction and wear tests of zirconia ceramics, and indicated that the ground surface ( $\mathrm{Ra} 1.12-1.48 \mu \mathrm{m})$ would generate more wear than the polished surface ( $\mathrm{Ra} 60-120 \mathrm{~nm}$ ) [29]. Janyavula et al. carried out the tribological tests to investigate the wear behavior of zirconia surfaces, demonstrating that the polished surface with Ra of $0.17 \mu \mathrm{m}$ led to less wear than the glazed surface with Ra of $0.76 \mu \mathrm{m}$ [30]. However, the surface quality involved in the above studies is relatively conventional, and researches on the effect of higher quality ceramic surfaces (e.g., nanoscale roughness) on friction and wear are very rare.

In recent years, many researches have been carried out on improving the surface quality of zirconia ceramics. Huh et al. compared the polishing efficiencies of the existing commercial polishing systems with different tools for polishing zirconia ceramics and showed that the lowest surface roughness of Ra $0.14 \mu \mathrm{m}$ was achieved [31]. Zucuni et al. investigated the influence of different finishing and polishing processes on surface roughness and topography of ground Y-TZP ceramics and achieved the polished surface roughness varied from $\mathrm{Ra} 1.214 \mu \mathrm{m}$ to $\mathrm{Ra} 0.326 \mu \mathrm{m}$ using a multistep process including grinding, finishing and polishing [32]. Fiocchi et al. presented a study that focus on the finishing process of 3Y-TZP ceramics by using an Ud-lap grinding process, and the experiments were carried out on a Fiocchi CNC Lap 
Grinder. In their study, the best finishing results i.e., Ra $60.63 \mathrm{~nm}$, was achieved [33]. Denkena et al. proposed a grinding-polishing process chain on a CNC machining tool for the manufacture of zirconia-toughened alumina total knee implants. A toric grinding tool and a silicone bond diamond polishing tool were used one after another, and the surface roughness of $\mathrm{Ra} 100 \mathrm{~nm}$ and $\mathrm{Ra} 8 \mathrm{~nm}$ were achieved, respectively [34]. However, due to the high hardness, brittleness and chemical inertness, processing and manufacturing of the zirconia ceramic surface especially for medical implants with curved surface are very difficult, and current technologies are difficult to efficiently achieve ultra-high surface quality $[17,35]$.

In this paper, a rapid preparation process of ultra-smooth surface of Y-TZP bioceramics was investigated, based on our previously developed dual-axis wheel polishing system. And the relevant friction and wear characteristics of the prepared ultra-smooth surfaces were also tested. Specifically, the effects of key process parameters on the machining performance were studied and the prepared surfaces were characterized using XRD, micro-hardness and SEM analysis. Besides, tribological tests in both dry and lubrication conditions were also carried out using a ball-on-plate reciprocating tribometer to demonstrate the wear and friction behaviors of the prepared surfaces. The coefficients of friction, wear amounts and wear tracks were measured and observed, and the wear mechanism was analyzed.

\section{Experimental details}

\subsection{Experimental setup}

The investigations on the preparation process of ultra-smooth Y-TZP bioceramic 
surfaces were carried out based on the self-developed high-efficiency dual-axis wheel polishing technology in the field of optical manufacturing. Its principle is shown in Fig. 1, and the other details of the technology can be found in our previous work [36].

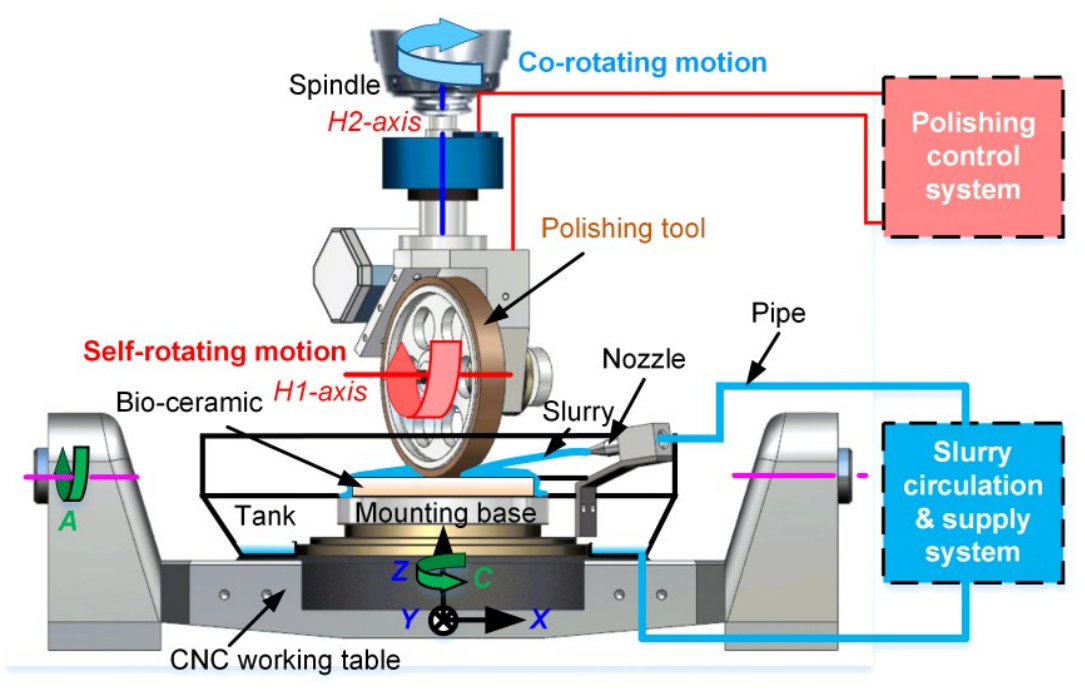

Fig. 1. Schematic illustration of the dual-axis wheel polishing technology.

During ultra-smooth finishing, the polishing wheel is in contact with the sample surface, and a certain tool offset (compression displacement) of the wheel is generated along the normal direction of the sample surface (see Fig. 2b). With the action of the polishing wheel's rotating motion, the submicron-scale polishing abrasives which are impregnated and carried by the polyurethane layer cut the sample surface, and the surface materials are removed in elastic or plastic forms. Combined with the utilized polishing path and the feed motion, the polishing wheel with a dual-axis rotating motion polishes the sample in a scanned form, as shown in Fig. 2. 


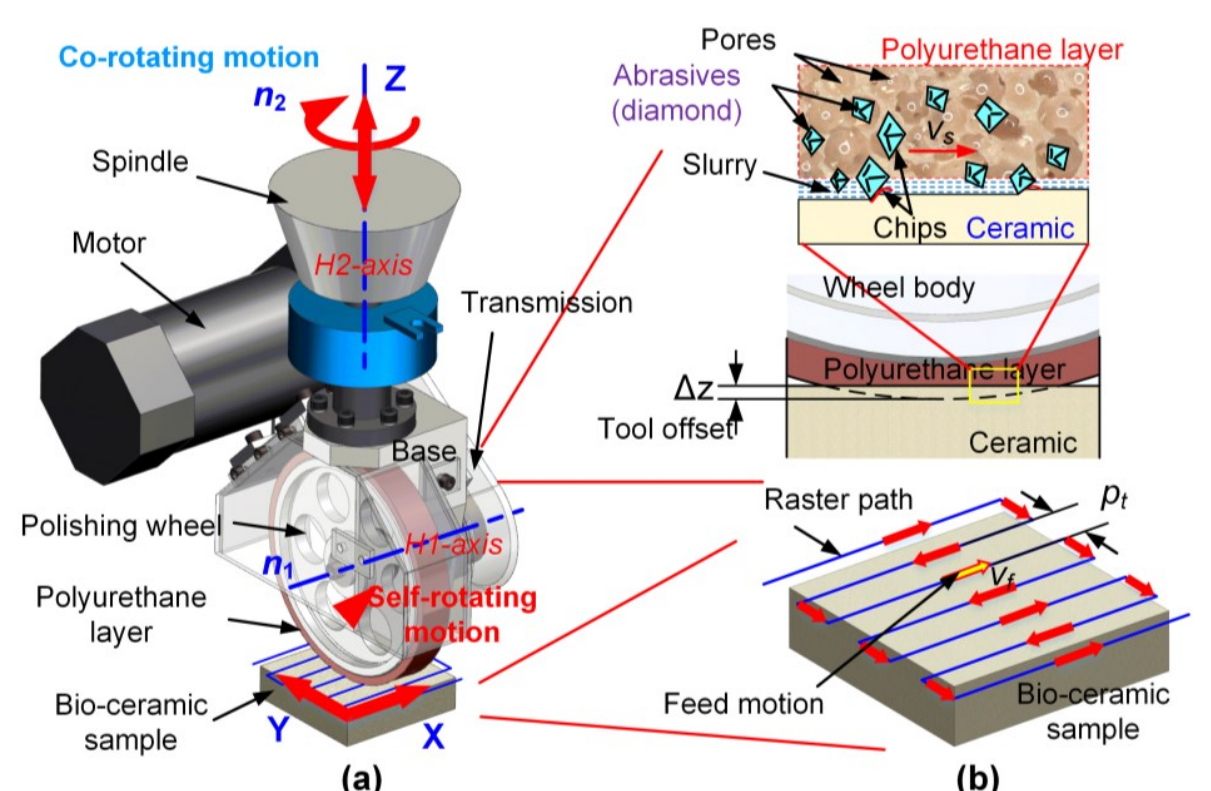

(a)

(b)

Fig. 2. Illustrations of (a) the dual-axis wheel finishing process for bioceramics;

(b) local details.

\subsection{Materials}

The sample material used in the study was flat Y-TZP bioceramic (Blue Whale Ceramic Technology Co., Ltd, China), whose property parameters are listed in Table 1. The dimension of the samples for polishing were $30 \mathrm{~mm}$ long, $30 \mathrm{~mm}$ wide and $5 \mathrm{~mm}$ thick. The surfaces being polished were fine ground, which had a flatness error of less than $1.5 \mu \mathrm{m}$ and a surface roughness of about $130 \mathrm{~nm}$ in $\mathrm{Ra}$ (in the study, the arithmetic average of the roughness profile, $\mathrm{Ra}$, was used as the indicator of surface roughness $[37$, 38]). The machining method and the achieved surface roughness are similar to those for the zirconia medical implant reported by reference [25, 39]. All the samples were rinsed with deionized water, and ultrasonically cleaned in alcohol solution, and dried, prior to and after polishing.

Table 1 Material properties of the Y-TZP bioceramic used (provided by the

$$
\text { manufacturer) [7] }
$$




\begin{tabular}{cccccc}
\hline Elastic & Poisson & Hardness/ & Fracture & Density & Expansion \\
Modulus/ & ratio & $\mathrm{GPa}$ & toughness/ & $\mathrm{g} / \mathrm{cm}^{3}$ & coefficient/ \\
$\mathrm{GPa}$ & & & $\mathrm{MPa} \cdot \mathrm{m}^{1 / 2}$ & & $\left(10^{-6} / \mathrm{K}\right)$ \\
\hline 210 & 0.3 & 11.5 & 10 & 5.95 & 10 \\
\hline
\end{tabular}

The polishing abrasive was diamond micro-powder (Saint-Gobain corporation, France) with an average particle size of $0.75 \mu \mathrm{m}$ (the distribution interval was $0.5-1$ $\mu \mathrm{m})$. The home-made polishing slurry consisted of deionized water, abrasive particles, polyethylene glycol (PEG) and polyvinylpyrrolidone (PVP). The slurry concentration used was 4 wt \% (1:25). And a magnetic agitator was used to stir the slurry during polishing process.

\subsection{Details of the process development tests of ultra-smooth surface preparation}

According to the Preston law, polishing pressure and polishing velocity are the two most important process parameters that affect the polishing process [40]. In DAWP, the polishing pressure is controlled by the offset of the polishing wheel, and the polishing velocity is mainly determined by the self-rotating motion of the wheel (the co-rotating motion of the polishing wheel mainly plays the role of auxiliary feed and its effect on polishing is indirect) $[36,41]$. Both have direct impacts on the polishing process. In this section, a series polishing tests were arranged to investigate the effect of the main process parameters (i.e., tool offset and wheel speed) on machining performance (including material removal rate and surface quality). Scanning polishing mode along a simple raster path was used (see Fig. 2b), and the pitch (interval) of the path $p t$ was $0.4 \mathrm{~mm}$. The rotating speed of the co-rotating motion $n_{2}$ was $60 \mathrm{r} / \mathrm{min}$. The feed velocity 
$v_{f}$ was $50 \mathrm{~mm} / \mathrm{min}$, and the total polishing time $T_{p}$ was $53 \mathrm{~min}$. The corresponding experimental arrangement details are listed in Table 2. The value range of the parameters in the table were determined by previous tests, and too large and too small values that are not conducive to the polishing process were avoided.

Table 2 Experimental arrangement of the polishing test

\begin{tabular}{cccc}
\hline Test No. & Test name & Tool offset $\Delta \mathrm{z} / \mathrm{mm}$ & Wheel speed $n_{1} / r \cdot \mathrm{min}^{-1}$ \\
\hline 1 & & 0.04 & \\
2 & The effect of & 0.06 & 700 \\
3 & tool offset & 0.08 & \\
4 & & 0.1 & 500 \\
5 & & & 600 \\
6 & The effect of & & 700 \\
7 & wheel speed & 0.06 & 800 \\
\hline
\end{tabular}

The polishing performance was systematically evaluated by analyzing the material removal rate, 3D surface topography and roughness, surface micro-topography, X-ray diffraction (XRD) patterns and micro-hardness.

The material removal rate (MRR) was calculated by using the weight measurement data of the sample before and after polishing, and a precision electronic balance (CP213, OHAUS, USA) with precision of $1 \mathrm{mg}$ was used.

$$
M R R=\frac{1000\left(m_{\mathrm{A}}-m_{\mathrm{B}}\right)}{\rho_{z} \cdot T_{p}}
$$


Where, MRR is the material removal rate, its unit is $\mathrm{mm}^{3} / \mathrm{min} ; m_{\mathrm{A}}$ and $m_{\mathrm{B}}$ are the weights of test sample before and after polishing, respectively, the unit is $g$; $\rho_{\mathrm{z}}$ is the density of Y-TZP bioceramic, the unit is $\mathrm{g} / \mathrm{cm}^{3} ; T_{p}$ is the total polishing time, the unit is $\min$.

The 3D surface topography and surface roughness were measured using a white-light interferometer (NewView $\left.{ }^{\mathrm{TM}} 7100, \mathrm{ZYGO}, \mathrm{USA}\right)[42,43]$, and the magnification of objective was $50 \times$. The number of measurement points was 5 , which were evenly distributed on the sample surface.

The surface morphology before and after polishing were observed by using a field emission scanning electronic microscope (MIRA 3, TESCAN, Czech) to investigate the material removal mechanism of the polishing process. And an X-ray diffractometer (D8 ADVANCE, Bruker, Germany) was used to further investigate the material crystal structure of the sample before and after polishing, and the sample which had been polished at tool offset of $0.06 \mathrm{~mm}$ and wheel speed of $600 \mathrm{r} / \mathrm{min}$ was used.

The micro-hardness of the sample surface was measured using a Vickers microhardness tester (Model 402 MVA, Wolpert Wilson Instruments, USA) with a load of $1000 \mathrm{gf}$ and dwell time of $10 \mathrm{~s}$. The Vickers hardness value was obtained as an average of 10 measurement points per test sample.

\subsection{Details of the tribological tests}

The tribological tests were conducted to comparatively investigate the friction and wear characteristics of the conventional surface (i.e., initial fine ground surface at submicroscale) and the prepared ultra-smooth surface (i.e., finished surface at subnano- 
scale).

A ball-on-plate reciprocating tribometer (UMT-2, Bruker, USA) was used to carry out the tests. The Y-TZP sample used $\left(30 \times 30 \times 5 \mathrm{~mm}^{3}\right)$ was mounted on the top of the sliding table of the tribometer. To simulate the ceramic-on-ceramic bearing configuration, a zirconia ceramic ball with a diameter of $12 \mathrm{~mm}$ was used as a counterpart. The schematic illustration diagram of the test is shown in Fig. 3. The test load set was $20 \mathrm{~N}$. The sliding frequency was $1 \mathrm{~Hz}$, and the sliding stroke was $10 \mathrm{~mm}$ (the parameters used refer to the reference $[25,44]$ ). The total test duration was 60 min. The ambient temperature set and humidity during the test were $24^{\circ} \mathrm{C}$ and $30 \%$ (laboratory environment), respectively. Before test, the sample and the zirconia ball were both ultrasonically cleaned in deionized water.

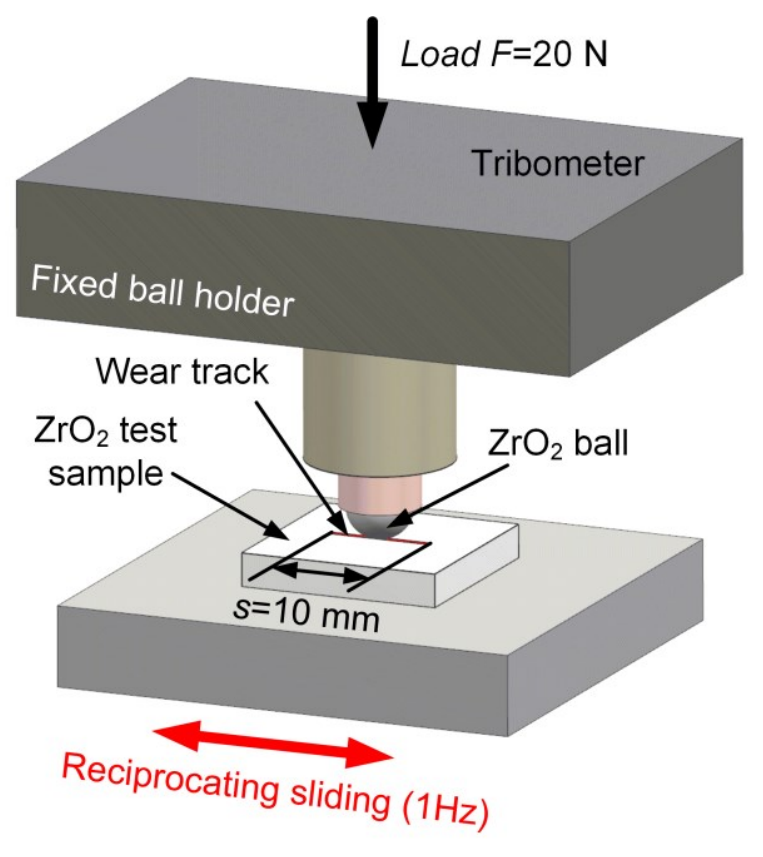

Fig. 3. Schematic illustration of the tribological test.

The sample with conventional surface (sub-micron roughness) and the sample with ultra-smooth surface (sub-nanometer roughness; polishing parameters: tool offset: 0.06 
mm, wheel speed: $600 \mathrm{r} / \mathrm{min}$ ) were selected to participate the tests. What's more, the test under dry friction and lubrication friction (68\# industrial white oil, Moroke, China) conditions were both considered. For the conventional surface, the sliding direction was perpendicular to the stripe-like grinding surface texture.

The test results included coefficient of friction (COF), characterization of wear track, and micro-morphology characterization of worn surface. Among them, the coefficient of friction result was directly exported by the used tribometer. A3D optical profilometer (MicroXAM-3D Phase Shift; ADE Co., USA) was used to measure the 3D topography and dimensions (average width and length, i.e., wear amount) of the generated wear track. The micro-morphology of the worn surface was observed by using a field emission scanning electron microscopy microscope (Sigma 300, Carl Zeiss, Germany) to further investigate the wear mechanisms generated under different conditions.

\section{Results and discussion}

\subsection{Material removal rates}

Fig. 4 shows the effect of tool offset on material removal rate. It can be seen that as the tool offset increases from $0.04 \mathrm{~mm}$ to $0.1 \mathrm{~mm}$, the MRR linearly increases from $0.088 \mathrm{~mm}^{3} / \min (0.53 \mathrm{mg} / \mathrm{min})$ to $0.191 \mathrm{~mm}^{3} / \mathrm{min}(1.14 \mathrm{mg} / \mathrm{min})$ accordingly. It can be explained that with the increase of tool offset, the force/pressure within the contact area between the wheel and the sample is also linearly increased [41], and then the load applied on the single abrasive grain becomes larger. Hence, according to the polishing theory $[36,45]$, much more material removal is generated in a linear law. 


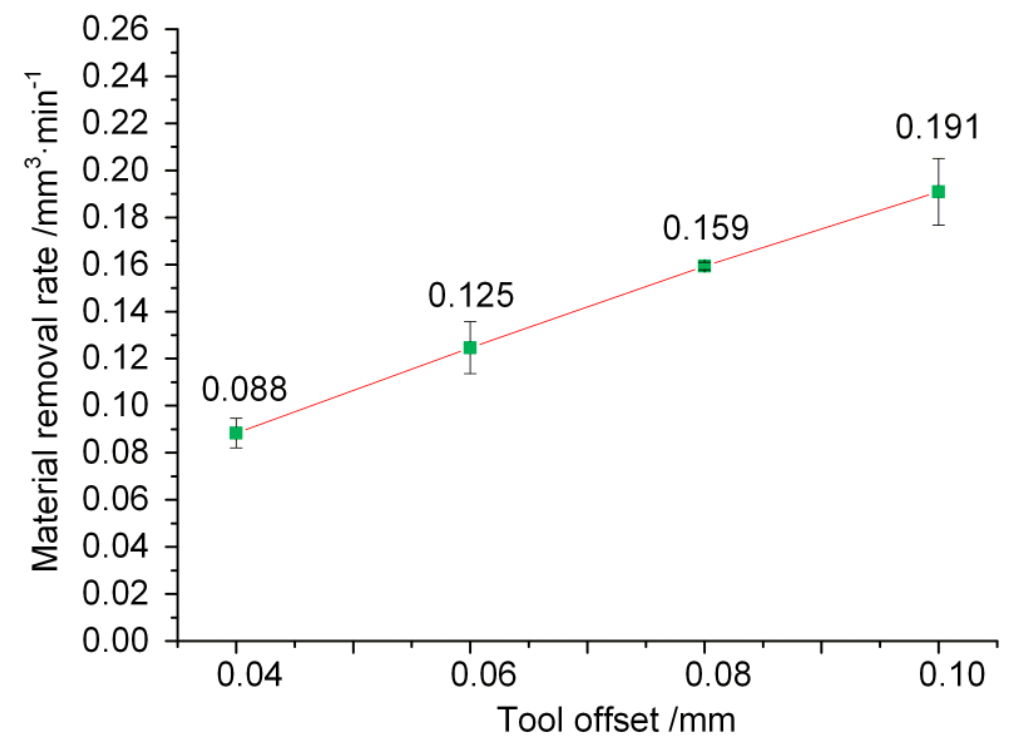

Fig.4. Material removal rate versus tool offset.

Fig. 5 shows the effect of wheel speed on the generated material removal rate. The MRR increases from $0.084 \mathrm{~mm}^{3} / \mathrm{min}(0.5 \mathrm{mg} / \mathrm{min})$ to $0.156 \mathrm{~mm}^{3} / \mathrm{min}(0.93 \mathrm{mg} / \mathrm{min})$ in an approximate linear relationship while the wheel speed increases from $500 \mathrm{r} / \mathrm{min}$ to $800 \mathrm{r} / \mathrm{min}$. As the wheel speed increases, more abrasives are carried into the polishing area to participate the material removal process in unit time. And in the case where other conditions remain the same, the number of abrasive grains involved in cutting process is approximately linear with the wheel speed, therefore, the linear increase of the material removal rate is achieved.

The above results are also consistent with the Preston hypothesis describing the material removal law in the polishing field. i.e., the material removal generated in unit time is proportional to the polishing pressure and polishing velocity [46]. It can be found from Fig. 4 and 5 that larger parameter value generates more material removal, which means deeper surface and sub-surface layer can be removed. 


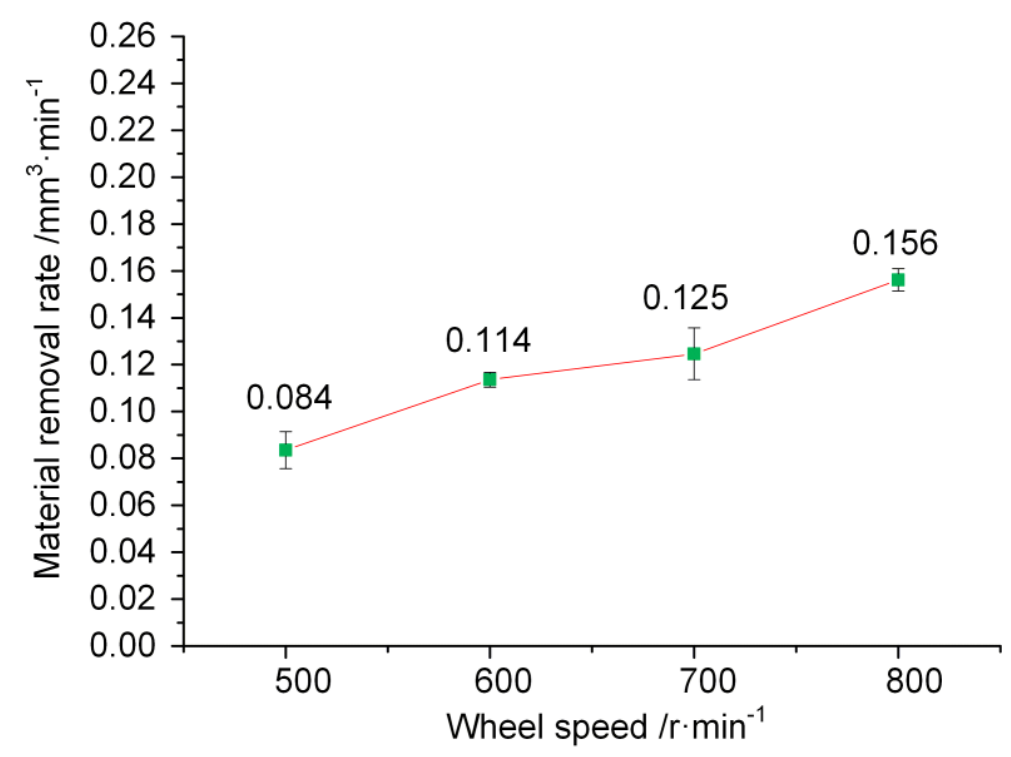

Fig.5. Material removal rate versus wheel speed.

\subsection{Surface topography and surface roughness}

Fig. 6 shows the appearance of the Y-TZP samples before and after polishing under different tool offsets, and it can be seen that mirror-like surfaces are achieved for all the samples after a short polishing duration of $53 \mathrm{~min}$.

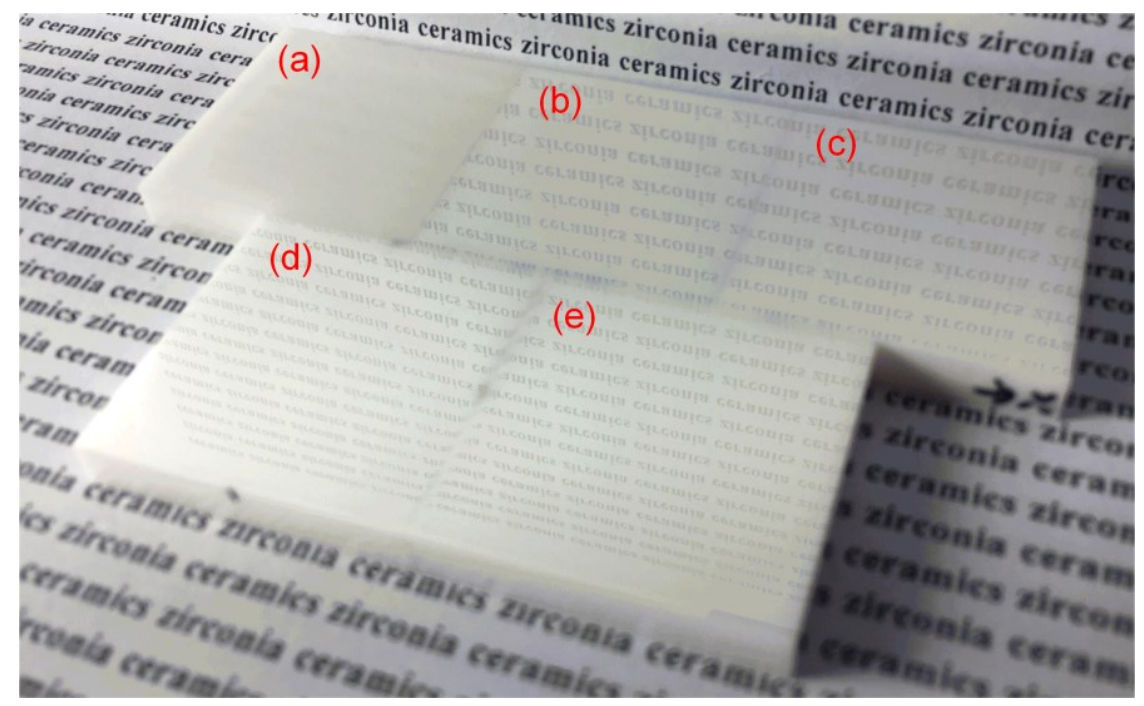

Fig. 6. Appearance of the Y-TZP samples before and after polishing under different

tool offsets: (a) initial surface; (b) $0.04 \mathrm{~mm}$; (c) $0.06 \mathrm{~mm}$; (d) $0.08 \mathrm{~mm}$; (e) $0.1 \mathrm{~mm}$.

The corresponding surface roughness measurement results are shown in Fig. 7. The average surface roughness of the initial fine ground surface (i.e., the conventional 
surface) is approximately Ra $129.3 \mathrm{~nm}$. After only one pass polishing, ultra-smooth surfaces [47-51] with sub-nanometer roughness are achieved for all tool offsets. As the tool offset increases from $0.04 \mathrm{~mm}$ to $0.1 \mathrm{~mm}$, the final surface roughness slightly increases from $\mathrm{Ra} 0.41 \mathrm{~nm}$ to $\mathrm{Ra} 0.44 \mathrm{~nm}$ with a high convergence rate of $99.7 \%$.

Fig. 8 shows the average surface roughness measurement results at different wheel speeds. With increasing the wheel speed from $500 \mathrm{r} / \mathrm{min}$ to $800 \mathrm{r} / \mathrm{min}$, the surface roughness value slightly increases from $\mathrm{Ra} 0.38 \mathrm{~nm}$ to $\mathrm{Ra} 0.43 \mathrm{~nm}$ accordingly. Besides, the highest convergence rate of $99.7 \%$ is also achieved.

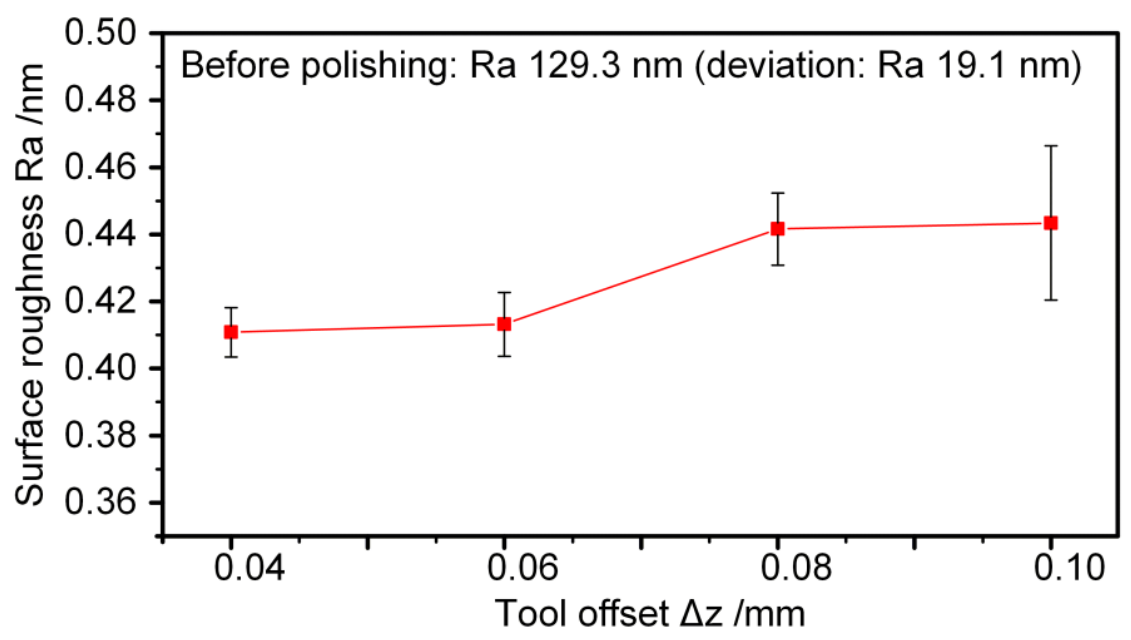

Fig. 7. Measured average surface roughness versus tool offset.

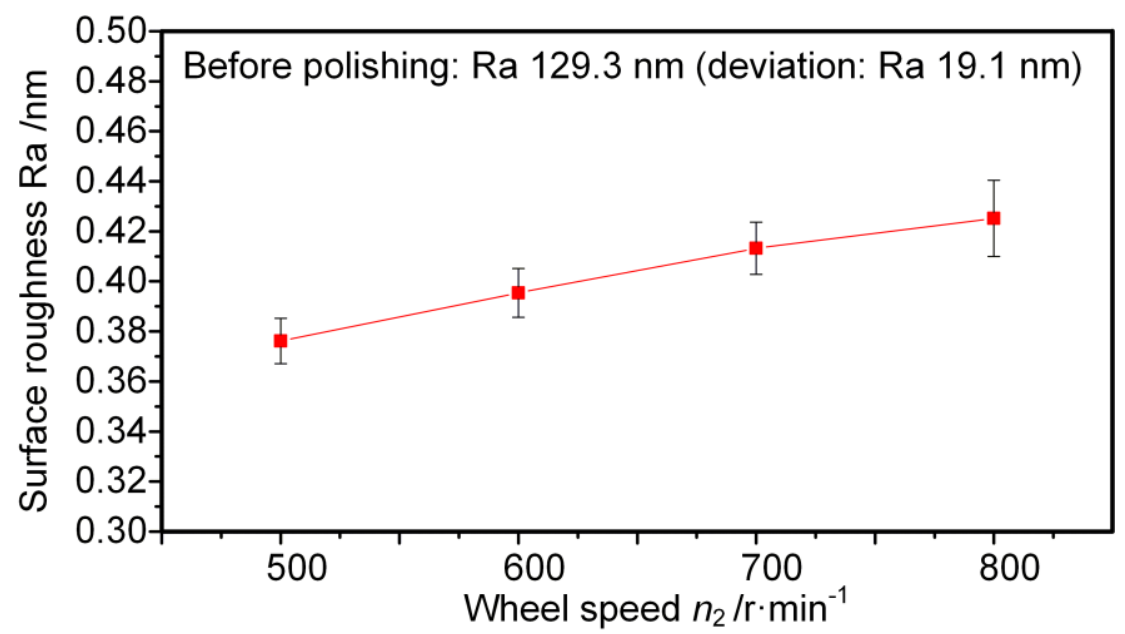

Fig. 8. Measured average surface roughness versus wheel speed. 
Fig. 9 shows the evolution of 3D surface topography with tool offset and wheel speed parameters. It can be seen that rough stripe-like ground texture with large amplitude exists on the representative initial surface before polishing. These rough unidirectional surface structures are totally removed after one pass polishing for all the polishing tests. And the achieved surface topographies are uniform and smooth.

To comprehensively analyze the above results, it can be found that the surface roughness and topography of polished surface are not sensitive to the change of these two parameters, and can always maintain a stable and low value (i.e., it can achieve high surface quality over a wide range of parameters). It can be explained that at each parameter, sufficient material removal occurs on the workpiece surface. The original surface features and damage layers are effectively removed, and the resulting polished surface is a new smooth surface generated in the bulk material [52]. In addition, the dual-axis movement of the polishing wheel and the smaller path pitch used make the surface features more uniform, and effectively eliminates the differences in surface texture produced under different process parameters. On the other hand, from a micro perspective, a larger tool offset will generate a larger polishing pressure, which increases the cutting depth of a single abrasive particle. A higher polishing wheel speed increases the number of abrasive particle cutting cycles per unit time. Hence, the probability of multiple abrasive particles cutting at the same location increases, and the cutting depth is also increased. Therefore, after polishing, some deeper valleys remained, making the surface roughness value slightly increase. 


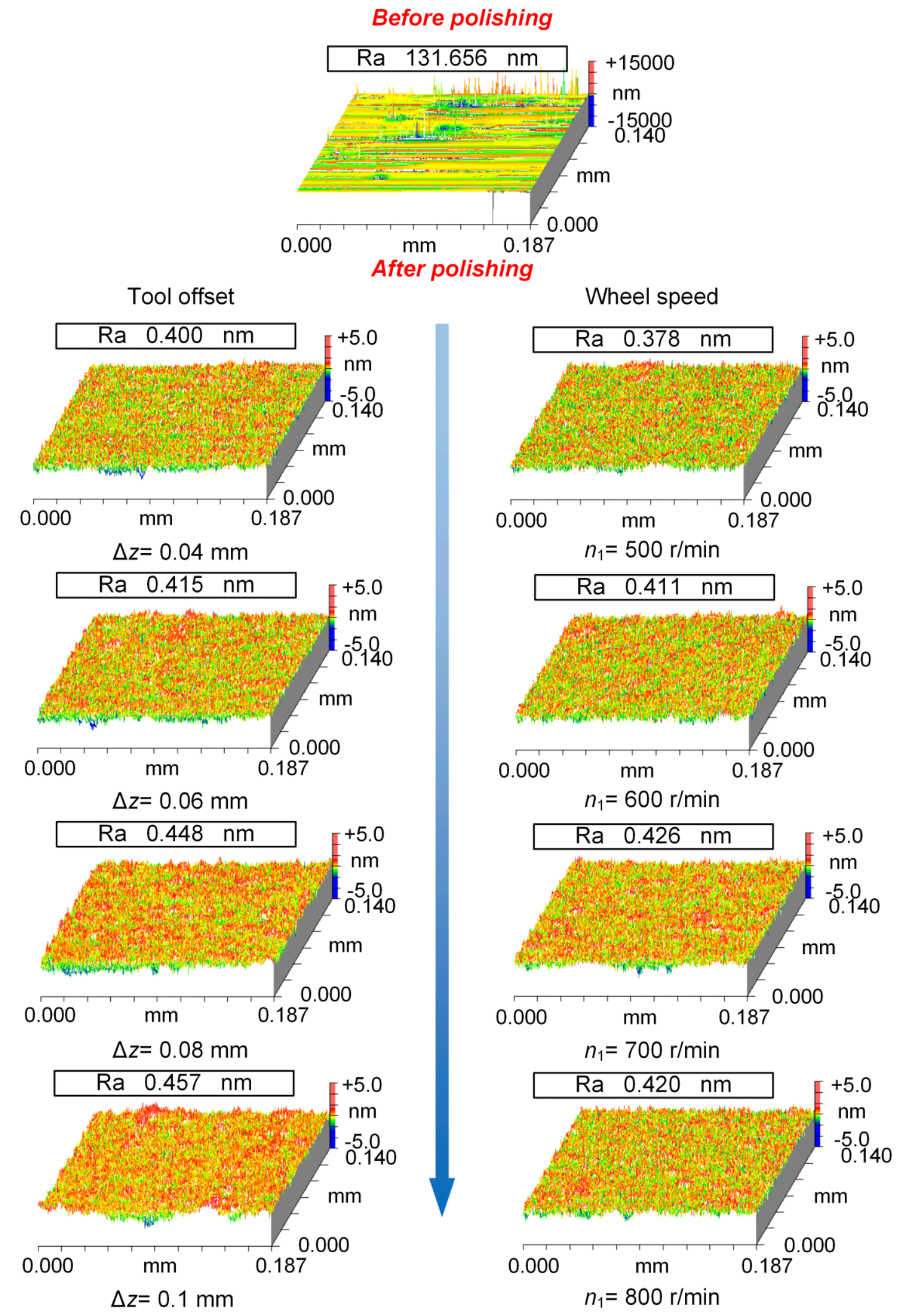

Fig. 9. Surface topography of the Y-TZP bioceramic samples before and after polishing under different tool offsets and wheel speeds. 


\subsection{SEM surface morphology}

In order to observe the morphology changes and better understand the material removal mechanism of the polishing process, SEM observations were carried out on the initial fine ground and the polished samples, and the results are displayed in Fig. 10.

Fig. 10a shows the morphology of initial fine ground surface. The stripe-like cutting grooves parallel to the cutting direction of grinding wheel are densely distributed on the entire surface. From the specific morphology details (see Fig. 10a1), we can clearly find that a mass of surface and sub-surface damages, e.g., cracks, pits, debris, brittle crushing exist on the surface. The existence of these textures and defects is the reason for the high initial surface roughness. More importantly, these defects may affect the lifespan and service performance of bioceramic parts, especially for bioceramic medical implant, hence, it must be effectively removed.

Fig. 10b e show the SEM morphologies under different tool offsets after one pass polishing. In all cases, the grinding induced surface textures and defects mentioned above have all been removed, resulting in a uniform, smooth surface. The pores existed are produced during sintering process which involves to the pressure and thermal change and crystalline phase transformation. Among them, there are a small number of cracks on the polished surface under smaller tool offset of $0.04 \mathrm{~mm}$ (see Fig. 10b). This can be explained that because the used small tool offset generates thinner material removal layer, hence some deeper grinding defects cannot be effectively removed. Or it may be the grain boundary cracks generated during sintering process. In addition, in the magnification picture (as displayed in Fig. 10b), it can be seen that there are a certain 
amount of plastic scratches on the polished surface, and no defects such as pit and fracture. Which indicates that the diamond abrasive grains remove the material from the sample surface during polishing process in a form of plastic mode. What's more, the defects existed on the polished surface under a large tool offset $(0.1 \mathrm{~mm})$ are grain boundary cracks which generated during the sintering process (see Fig. 10e).
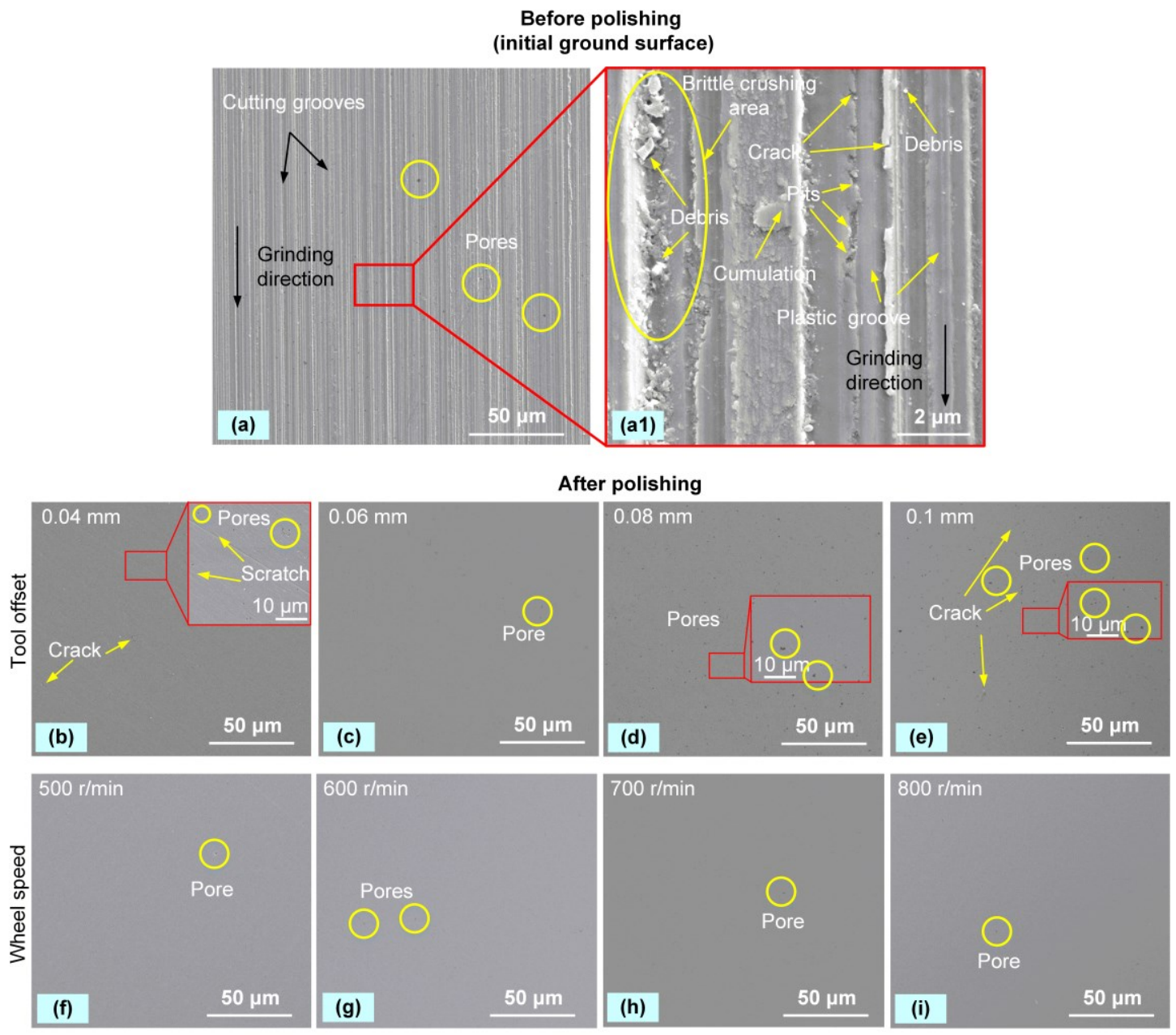

Fig. 10. SEM morphology images of the Y-TZP bioceramic samples before and after polishing under different tool offsets and wheel speeds.

Fig. 10f $\sim$ display the surface morphology generated under different wheel speeds. For each wheel speed, the polished surface is uniform and smooth, and the initial ground texture and defects are totally removed. In summary, the dual-axis wheel 
polishing process can steadily realize the rapid preparation of ultra-smooth surface of Y-TZP bioceramics.

\subsection{Micro-hardness}

Fig. 11 shows the micro-hardness measurement results with tool offset and wheel speed. The surface hardness before and after polishing is slightly higher than the hardness data provided by the manufacturer. The micro-hardness of the initial ground surface is $12.86 \mathrm{GPa}$. After polishing, the hardness of the polished surface with different tool offsets and wheel speeds are all reduced. This can be explained that, during grinding process the machining hardening and strengthening actions take place on entire surface and sub-surface layer of the sample, hence, producing higher surface hardness. After polishing, the hardening layer is effectively removed, and due to the gentle characteristic of the polishing process, new hardened layer isn't produced. Therefore, the surface hardness value is reduced. The variation trend of the results is in agreement with the finding of the reference [53], which reported that the ground surface possesses a higher hardness value than the polished surface in an ultra-precision grinding process of transparent ceramics.

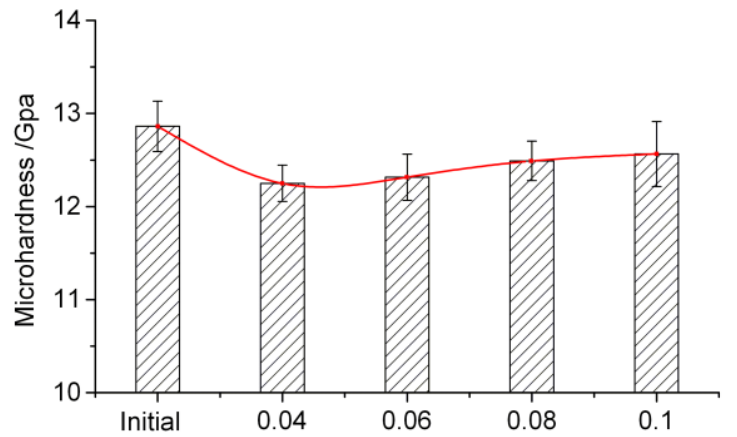

(a) Tool offset $/ \mathrm{mm}$

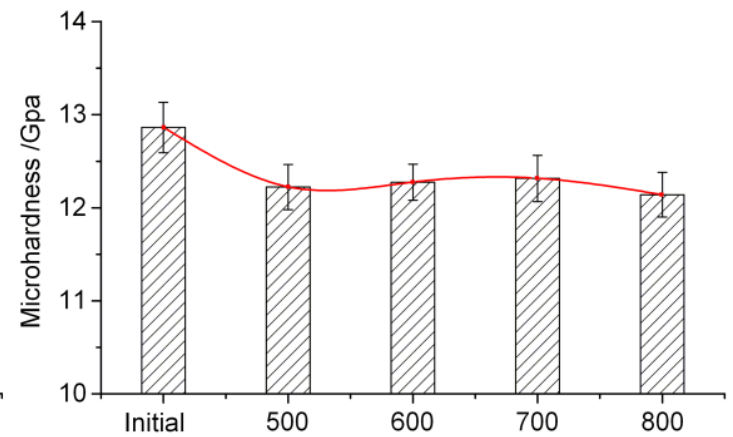

(b) Wheel speed /rpm

Fig. 11. Micro-hardness measurement results of the samples before and after polishing under different tool offsets and wheel speeds. 


\subsection{XRD analysis}

The XRD patterns of the sample surface before and after one pass polishing are shown in Fig. 12. It can be seen that the crystal phase composition of the initial fine ground surface and the polished surface are the same basically. The main diffraction peaks appear at $2 \theta=30.2^{\circ}, 35.2^{\circ}, 50.2^{\circ}, 60.1^{\circ}, 62.8^{\circ}, 74.4^{\circ}$ and $81.7^{\circ}$. From the results, it can be concluded that the main phase composition of the ceramics surface is stable tetragonal zirconia $\left(\mathrm{t}-\mathrm{ZrO}_{2}\right)$. What's more, it is confirmed that the dual-axis wheel polishing process would not cause the occurrence of phase transformations of the $\mathrm{Y}$ TZP bioceramic surface.

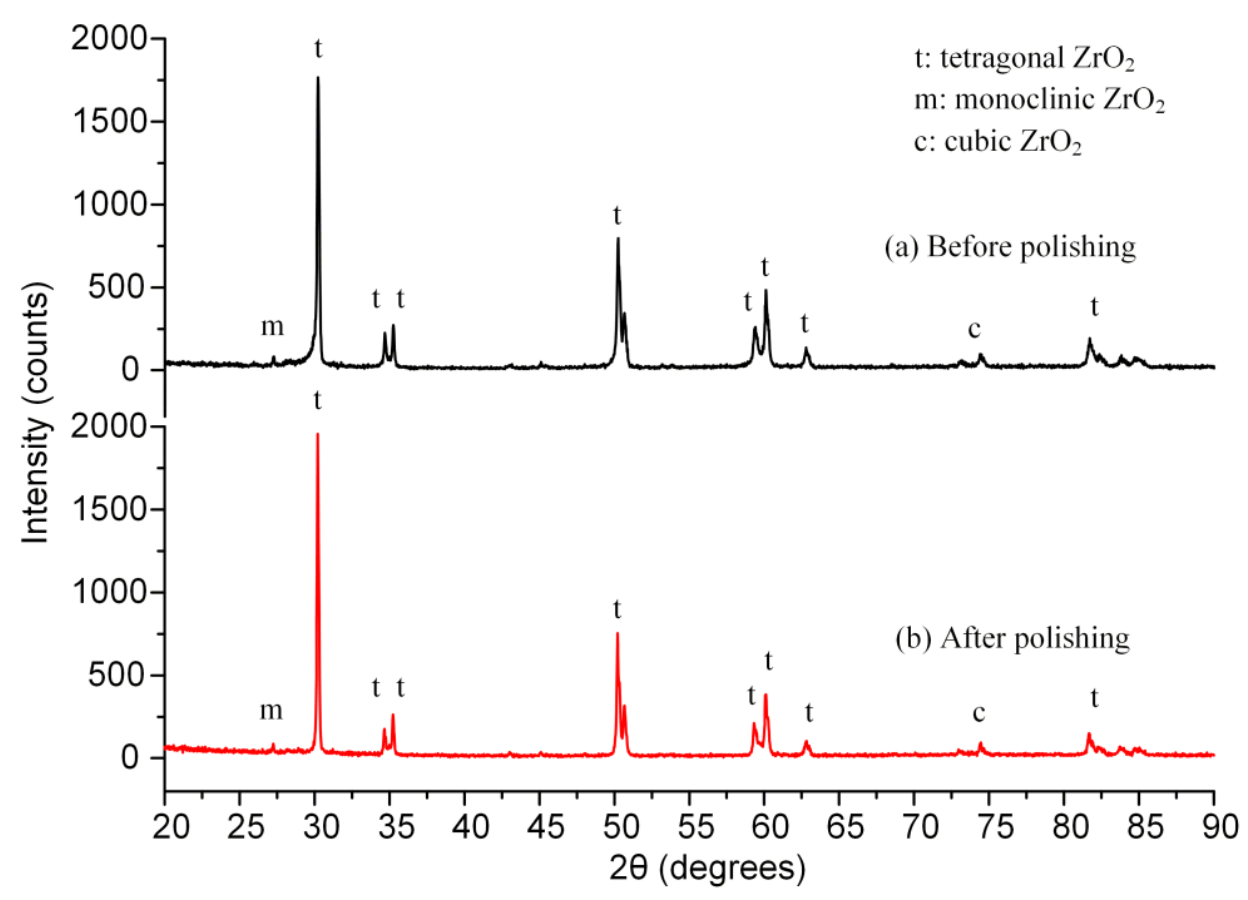

Fig. 12. X-ray diffraction pattern of samples surfaces before and after polishing.

\subsection{Friction and wear behavior}

The width and the depth of the wear track generated during friction process represent the surface wear resistance, and the smaller the size is, the better the surface wear performance is. Fig. 13 shows the 3D-topography measurement results of wear tracks 
generated on the conventional surface (the initial fine ground surface) and the prepared ultra-smooth surface. And Fig. 14 displays the corresponding average dimension (width and depth) measurement data of the wear tracks. It is noteworthy that the wear track (groove) generated on the conventional surface is much deeper and more obvious than that on the ultra-smooth surface, both in dry friction and lubrication conditions. Among them, under dry friction condition, the conventional surface generates the maximum wear width and depth values of $0.48 \mathrm{~mm}$ and $0.97 \mu \mathrm{m}$, respectively. And the ultrasmooth surface generates lower width value of $0.34 \mathrm{~mm}$ and much lower depth value of $0.15 \mu \mathrm{m}$. Under lubrication condition, the wear width and depth generated on conventional surface are $0.44 \mathrm{~mm}$ and $0.66 \mu \mathrm{m}$, respectively. And the ultra-smooth surface generates lowest wear width and depth values of $0.18 \mathrm{~mm}$ and $0.07 \mu \mathrm{m}$, respectively.

(a)

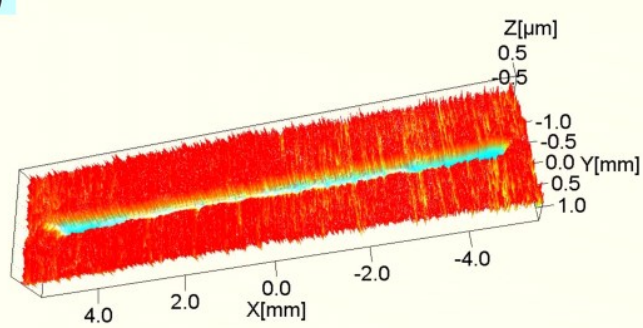

(c)

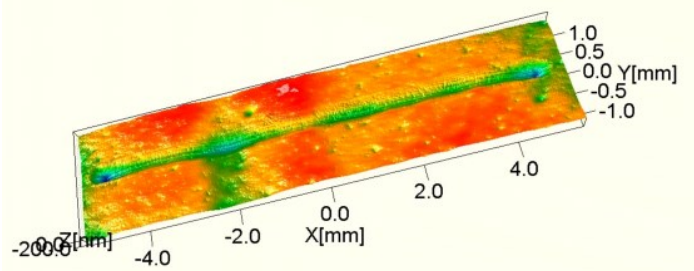

(b)

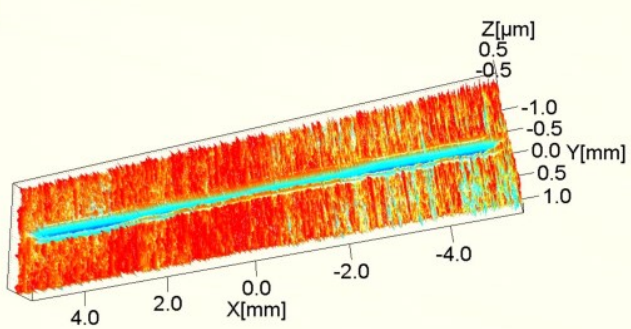

(d)

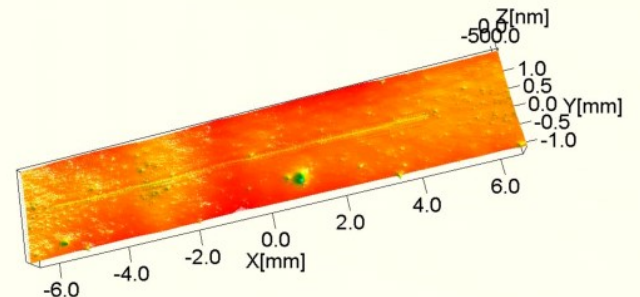

Fig. 13. Representative 3D-topography of wear tracks under different surface status (a) conventional surface (dry friction) (b) conventional surface (lubrication) (c) ultra- 
smooth surface (dry friction) (d) ultra-smooth surface (lubrication).

Therefore, it can be concluded that, in contrast to the conventional surface, the wear volume generated on the prepared ultra-smooth surface is greatly reduced. Besides, under lubrication condition, in contrast to the cases under dry friction condition, the wear volume generated on both the conventional and the ultra-smooth surfaces are reduced, and the ultra-smooth surface achieves a greater reduction. The prepared ultrasmooth surface has much better wear-resistant behavior than the conventional surface with sub-micrometer roughness in actual use, so it is expected to improve the service performance of bioceramic implants.

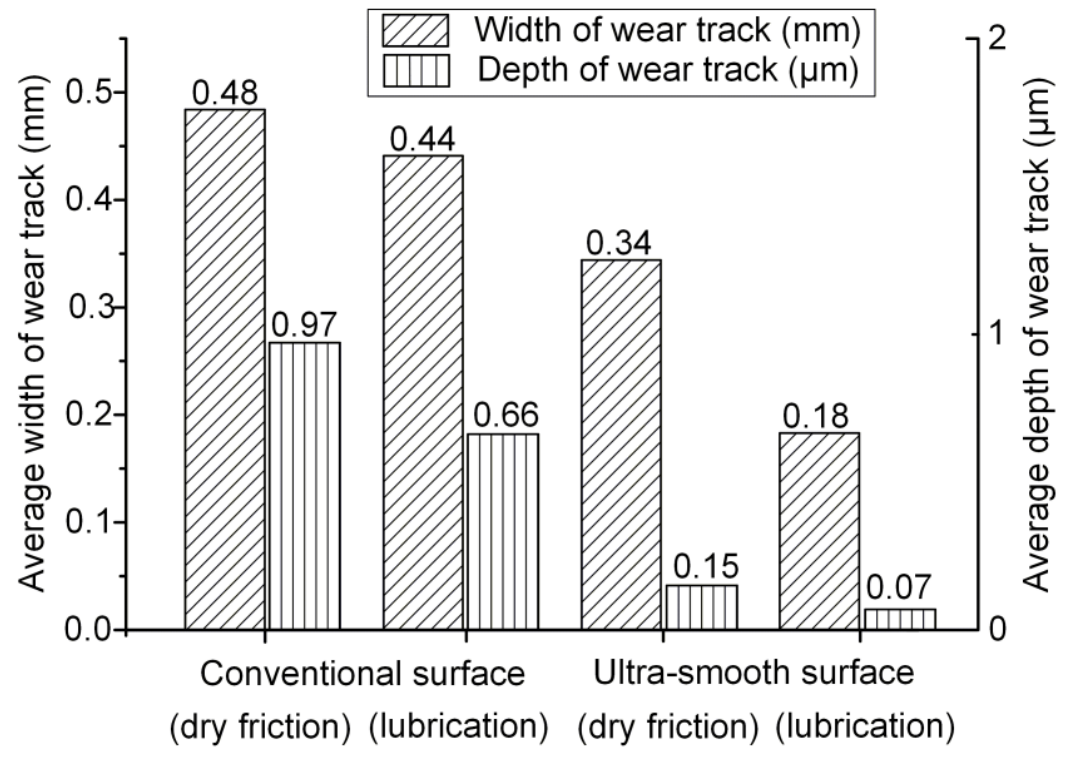

Fig. 14. Measured average dimension of the generated wear tracks under different surface status and lubrication conditions.

Fig. 15 shows the representative evolution curves of the friction coefficient with sliding time (distance) under different conditions. And the corresponding average COF results are displayed in Fig. 16. The results indicate that under dry friction condition, both for the conventional and the ultra-smooth surfaces, the coefficient of friction 
produced are much higher. The average COF of the conventional surface and the ultrasmooth surface are 0.289 and 0.216 , respectively (see Fig. 16). In addition, the amplitude of the COF curves are also higher (see Fig. 15), and showing a continuous rise state (without entering a true steady-state). This may be related to the presence of continuous adhesive wear (see Fig. 17), which reduces the smoothness of the interface and continues to increase wear.

Under lubrication conditions, both the conventional and ultra-smooth surfaces achieve a very low average COF value of 0.122 (which are $58 \%$ and $44 \%$ less than those under dry friction condition, respectively). The COF curves have a very low amplitude and oscillation, and enters a steady-state regime after a very short runningin time. Beside, as sliding time increases, the COF curves remain stable. Consequently, it indicates that the addition of the lubrication fluid can effectively improve the surface tribological behavior.

Under dry friction condition, the COF curve's amplitude of the conventional surface is higher than that of the ultra-smooth surface. In addition, it can be seen that higher oscillations are generated on the COF curve of the conventional surface, which means more severe adhesion and material transfer actions are occurred during the friction process [54]. Under lubrication condition, the amplitude and oscillation level of COF curves of the conventional surface and the ultra-smooth surface are very similar, i.e., low and steady. 


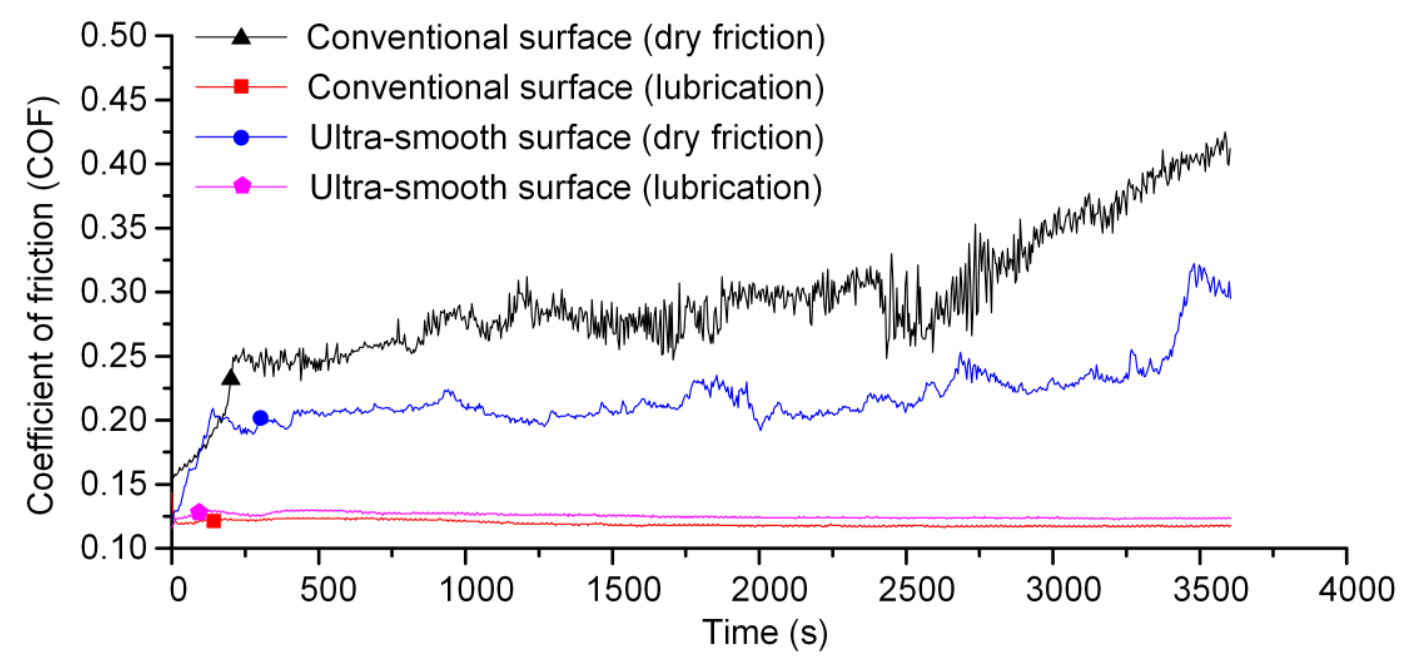

Fig. 15. Representative evolution curves of COF with sliding time (distance) under different conditions.

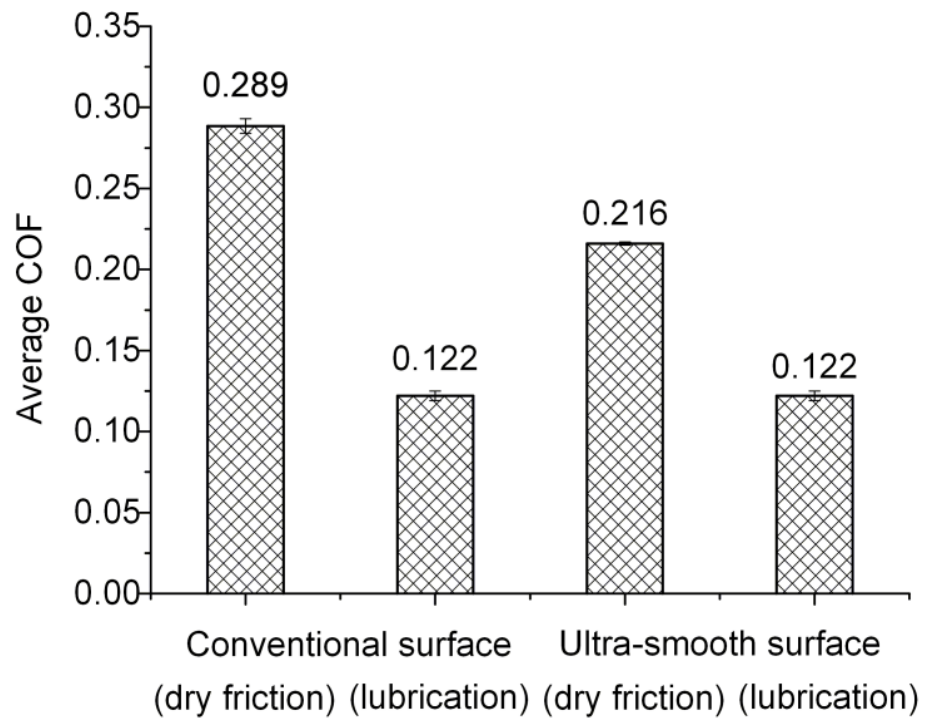

Fig. 16. Average COF of the samples surfaces under different conditions.

In summary, with the same lubrication condition (dry friction or lubrication friction), the COF of the prepared ultra-smooth surface is smaller than that of the conventional surface. It indicates that to achieve ultra-smooth surface can effectively improve the tribological behavior of the bioceramic samples.

The SEM images of worn surfaces generated under different conditions are shown in Fig. 17. The first, the second and the third columns respectively show low, medium and 
high-magnification worn morphologies of the wear track. In addition, red arrows in the figures indicate the direction of the sliding motion.
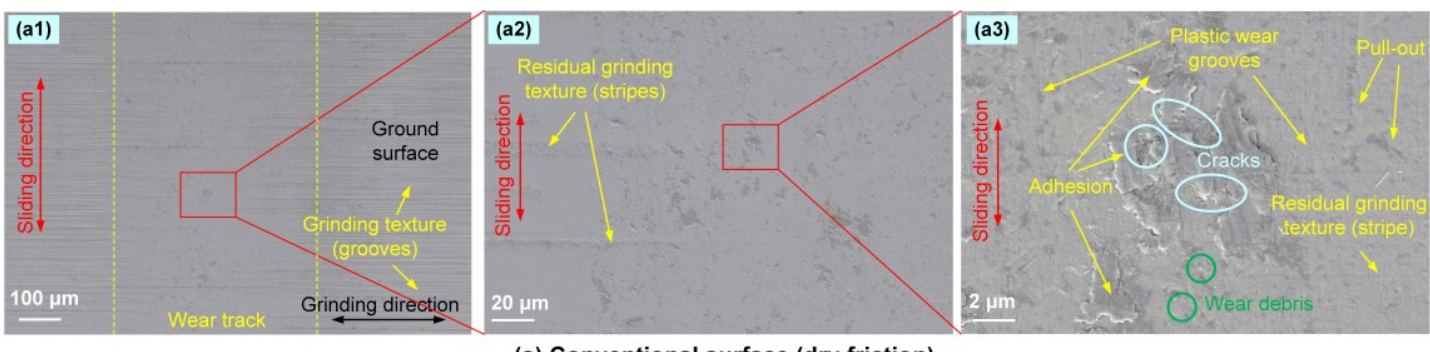

(a) Conventional surface (dry friction)
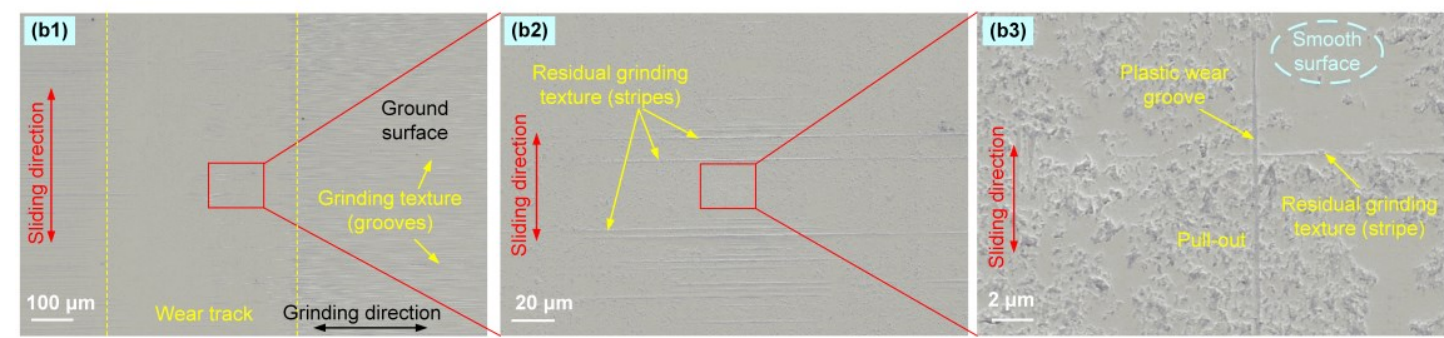

(b) Conventional surface (lubrication)
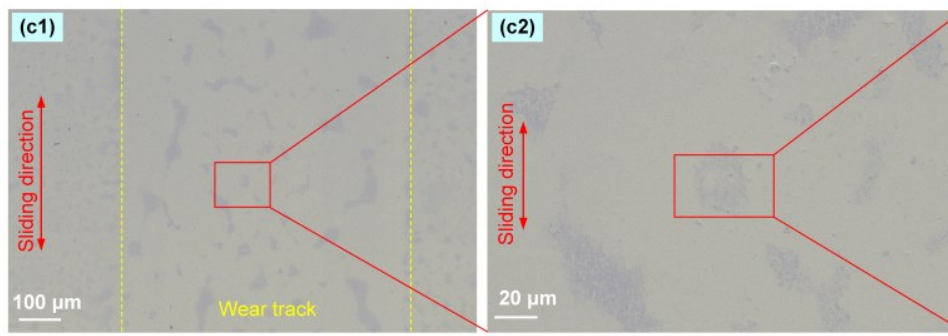

(c) Ultra-smooth surface (dry friction)
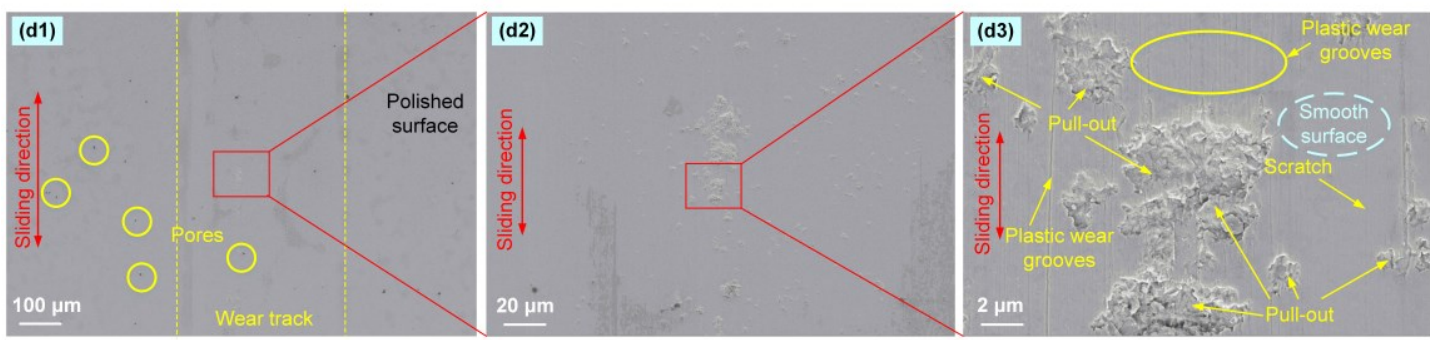

(d) Ultra-smooth surface (lubrication)

Fig. 17. SEM morphology images of the wear track and the local details under different conditions.

It can be seen that for the conventional surfaces (Fig. 17a and b), the generated wear track is perpendicular to the initial stripe-like grinding texture. And the texture within the track is substantially removed (as shown in Fig. 17 al and b1). From the magnification picture of the middle area of the track, it can be observed that there are 
lots of wear defects widely distributed on the worn surface (as shown in Fig. 17 a2 and b2). Among them, the dimension of the defects generated on the surface under lubrication condition (Fig.17 a2) are much smaller than that on the surface under dry friction condition (Fig.17 b2), but the distributions are denser. Further magnifying the worn surface (Fig. $17 \mathrm{a} 3$ and b3), it can be observed that there are varies of defects such as material adhesions, pull-outs, plastic wear grooves, scratches, fatigue micro-cracks generated on the surface under dry friction condition, and the entire surface is very rough. This shows that the wear of the surface under dry friction condition is mainly dominated by the abrasive wear and the adhesive wear. For lubricating friction surfaces, there are only material pull-outs and plastic wear groove defects, and the unworn surface remains smooth. Therefore, the main wear mechanism is abrasive wear.

For the prepared ultra-smooth surface (see Fig. 17c and d), the resulting macroscopic morphology of wear tracks is substantially consistent with the surrounding polished surface morphology. The degree of wear is much better than that of the conventional surface (as shown in Fig. $17 \mathrm{c} 2$ and d2), and the wear is relatively slight. In the magnification view (Fig. $17 \mathrm{c} 3$ and d3), it can be seen that under dry friction condition, wear defects such as material adhesions (accumulation), plastic wear grooves, scratches, material peeling (pull-outs) are generated on the worn surface, and the entire surface is very rough. Therefore, the main wear forms are abrasive wear and adhesive wear. What's more, the direction of the plastic wear grooves generated are not exactly the same as the sliding direction, and there are a number of residual hard wear debris presented inside the groove. It means that three-body wear actions which exacerbate 
the wear process of the surface take place. Under the lubrication condition, there are only material pull-outs and plastic wear scratches generated on the worn surface, and the unworn surface is quite smooth. It indicates that the main surface wear form is abrasive wear.

Therefore, combined with the results mentioned above, it can be concluded that with the aid of lubricants, the prepared ultra-smooth surface achieves a much smaller friction coefficient, and much less wear volume, indicating that the wear resistance of the surface is significantly improved, compared to the conventional surface. More importantly, the effect of wear debris due to excessive wear on the tissue surrounding the medical implant is expected to be effectively mitigated.

\section{Conclusions}

In this paper, a rapid preparation process of ultra-smooth surface of Y-TZP bioceramics was investigated, based on our previously developed dual-axis wheel polishing system. The preparation process development, and the friction and wear behaviors of the ultra-smooth surfaces were experimentally investigated. The following conclusions can be drawn:

- Ultra-smooth surface with sub-nanometer roughness can be steadily achieved at all main process parameters (i.e., tool offset and wheel speed) after only one pass polishing of $53 \mathrm{~min}$. And the maximum convergence rate of $99.7 \%$ on roughness from $\mathrm{Ra} 129.3 \mathrm{~nm}$ down to $\mathrm{Ra} 0.38 \mathrm{~nm}$ was achieved. It indicates that the dualaxis wheel polishing process can achieve high surface quality over a wide range of process parameters. 
- High material removal rates can be achieved during the preparation of ultrasmooth surfaces. The material removal rate increased linearly with the tool offset and the wheel speed. The maximum MRRs under the two parameters can reach 1.14 and $0.93 \mathrm{mg} / \mathrm{min}$, respectively.

- The material characterization results show that the original grinding features and defects were effectively removed after processing, leaving a smooth and uniform polished surface. Moreover, the hardness of the bulk material was restored; besides, the proposed preparation process does not cause a phase change of the material, and ensures the stability of the material composition.

- The wear resistance of the prepared ultra-smooth surface was significantly improved, in comparison to the conventional sub-micron surface. The worn tracks on the conventional surface were much deeper and wider than that on the ultra-smooth surface, under both dry and lubrication conditions in the tribological tests. For the ultra-smooth surfaces under the lubrication condition, the lowest wear width and depth were $0.18 \mathrm{~mm}$ and $0.07 \mu \mathrm{m}$, respectively, and the lowest COF of 0.122 was achieved.

The results confirmed the DAWP process can effectively overcome the problem of low efficiency in the multiple process chain commonly reported in other literature studies. The formed technical scheme and process parameters are expected to provide guidance for implant manufacturers to improve the manufacturing efficiency and cost performance of next generation free-form ceramic joint implant products, and promote the clinical application of ceramic joint products. Besides, the results also prove that 
the prepared ultra-smooth surfaces can effectively reduce the wear of ceramic material. Hence, the use of ceramic joint implant product with ultra-smooth bearing surfaces is expected to reduce the probability of aseptic loosening of implants in patients, thereby reducing the health risks and additional costs of the patients caused by secondary surgery.

Future research works will focus on the manufacture of free-form ceramic joint implants. A multi-axis DAWP system under development will be applied to manufacture free-form ultra-smooth bearing surface, and an existing multi-axis grinding machine will be used for the initial machining of the bearing surface. Besides, the polishing parameter used will be based on the research results of this study.

\section{Acknowledgement}

The authors would like to thank the National Science-Technology Support Plan of China (No. 2012BAF18G00) for the financial support of this work.

\section{References}

[1] Bian Y-Y, Zhou L, Zhou G, Jin Z-M, Xin S-X, Hua Z-K, et al. Study on biocompatibility, tribological property and wear debris characterization of ultra-lowwear polyethylene as artificial joint materials. Journal of the mechanical behavior of biomedical materials. 2018;82:87-94.

[2] Diomidis N, Mischler S, More N, Roy M. Tribo-electrochemical characterization of metallic biomaterials for total joint replacement. Acta biomaterialia. 2012;8:852-9.

[3] Liu F, Feng L, Wang J. A computational parametric study on edge loading in ceramic-on-ceramic total hip joint replacements. Journal of the mechanical behavior of 
biomedical materials. 2018;83:135-42.

[4] Kumar P, Ahuja IS, Singh R. Experimental investigations on hardness of the biomedical implants prepared by hybrid investment casting. Journal of Manufacturing Processes. 2016;21:160-71.

[5] Pilz V, Hanstein T, Skripitz R. Projections of primary hip arthroplasty in Germany until 2040. Acta orthopaedica. 2018;89:308-13.

[6] De Aza A, Chevalier J, Fantozzi G, Schehl M, Torrecillas R. Crack growth resistance of alumina, zirconia and zirconia toughened alumina ceramics for joint prostheses. Biomaterials. 2002;23:937-45.

[7] Lu A, Gao Y, Jin T, Luo X, Zeng Q, Shang Z. Effects of surface roughness and texture on the bacterial adhesion on the bearing surface of bio-ceramic joint implants: An in vitro study. Ceramics International. 2019.

[8] Affatato S, Ruggiero A, Merola M. Advanced biomaterials in hip joint arthroplasty. A review on polymer and ceramics composites as alternative bearings. Composites Part B: Engineering. 2015;83:276-83.

[9] Kurtz SM, Kocagöz S, Arnholt C, Huet R, Ueno M, Walter WL. Advances in zirconia toughened alumina biomaterials for total joint replacement. Journal of the mechanical behavior of biomedical materials. 2014;31:107-16.

[10] Pachaury Y, Tandon P. An overview of electric discharge machining of ceramics and ceramic based composites. Journal of Manufacturing Processes. 2017;25:369-90. [11] Singh D, Singh R, Boparai KS. Development and surface improvement of FDM pattern based investment casting of biomedical implants: A state of art review. Journal 
of Manufacturing Processes. 2018;31:80-95.

[12] Axinte D, Guo Y, Liao Z, Shih AJ, M'Saoubi R, Sugita N. Machining of biocompatible materials—Recent advances. CIRP Annals. 2019.

[13] Willmann G, Früh H, Pfaff H. Wear characteristics of sliding pairs of zirconia (YTZP) for hip endoprostheses. Biomaterials. 1996;17:2157-62.

[14] Huang X-q, Yang H-y, Luo T, Huang C, Tay FR, Niu L-n. Hollow mesoporous zirconia delivery system for biomineralization precursors. Acta biomaterialia. 2018;67:366-77.

[15] Branco A, Moreira V, Reis J, Colaço R, Figueiredo-Pina C, Serro A. Influence of contact configuration and lubricating conditions on the microtriboactivity of the zirconia-Ti6Al4V pair used in dental applications. Journal of the mechanical behavior of biomedical materials. 2019;91:164-73.

[16] Demarbaix A, Rivière-Lorphèvre E, Ducobu F, Filippi E, Petit F, Preux N. Behaviour of pre-sintered Y-TZP during machining operations: Determination of recommended cutting parameters. Journal of Manufacturing Processes. 2018;32:85-92. [17] Huang H, Liu Y. Experimental investigations of machining characteristics and removal mechanisms of advanced ceramics in high speed deep grinding. International Journal of Machine Tools and Manufacture. 2003;43:811-23.

[18] Huang H. Machining characteristics and surface integrity of yttria stabilized tetragonal zirconia in high speed deep grinding. Materials Science and Engineering: A. 2003;345:155-63.

[19] Yang F, Wu W, Cao L, Huang Y, Zhu Z, Tang T, et al. Pathways of macrophage 
apoptosis within the interface membrane in aseptic loosening of prostheses. Biomaterials. 2011;32:9159-67.

[20] Buller LT, Rao V, Chiu Y-F, Nam D, McLawhorn AS. Primary Total Knee Arthroplasty Performed Using High-Viscosity Cement is Associated With Higher Odds of Revision for Aseptic Loosening. The Journal of arthroplasty. 2019.

[21] Chethan K, Shenoy BS, Bhat NS. Role of different orthopedic biomaterials on wear of hip joint prosthesis: a review. Materials Today: Proceedings. 2018;5:20827-36. [22] Bahraminasab M, Sahari B, Edwards K, Farahmand F, Arumugam M. Aseptic loosening of femoral components-Materials engineering and design considerations. Materials \& Design. 2013;44:155-63.

[23] Su C-Y, Chen C-C, Huang Y-L, Chen S-W, Fang H-W. Optimization of biomolecular additives for a reduction of friction in the artificial joint system. Tribology International. 2017;111:220-5.

[24] Qiu M, Chyr A, Sanders AP, Raeymaekers B. Designing prosthetic knee joints with bio-inspired bearing surfaces. Tribology international. 2014;77:106-10.

[25] Roy T, Choudhury D, Ghosh S, Mamat AB, Pingguan-Murphy B. Improved friction and wear performance of micro dimpled ceramic-on-ceramic interface for hip joint arthroplasty. Ceramics International. 2015;41:681-90.

[26] Ghosh S, Abanteriba S, Wong S, Houshyar S. Selective laser melted titanium alloys for hip implant applications: Surface modification with new method of polymer grafting. Journal of the mechanical behavior of biomedical materials. 2018;87:312-24. [27] Mazumder S, Barad BB, Show BK, Mandal N. Tribological property enhancement 
of 3Y-TZP ceramic by the combined effect of $\mathrm{CaF} 2$ and $\mathrm{MgO}$ phases. Ceramics International. 2019;45:13447-55.

[28] Dong Y, Svoboda P, Vrbka M, Kostal D, Urban F, Cizek J, et al. Towards nearpermanent CoCrMo prosthesis surface by combining micro-texturing and low temperature plasma carburising. Journal of the mechanical behavior of biomedical materials. 2016;55:215-27.

[29] Preis V, Behr M, Handel G, Schneider-Feyrer S, Hahnel S, Rosentritt M. Wear performance of dental ceramics after grinding and polishing treatments. Journal of the mechanical behavior of biomedical materials. 2012;10:13-22.

[30] Janyavula S, Lawson N, Cakir D, Beck P, Ramp LC, Burgess JO. The wear of polished and glazed zirconia against enamel. The Journal of prosthetic dentistry. 2013;109:22-9.

[31] Huh Y-H, Park C-J, Cho L-R. Evaluation of various polishing systems and the phase transformation of monolithic zirconia. The Journal of prosthetic dentistry. 2016;116:440-9.

[32] Zucuni CP, Dapieve KS, Rippe MP, Pereira GKR, Bottino MC, Valandro LF. Influence of finishing/polishing on the fatigue strength, surface topography, and roughness of an yttrium-stabilized tetragonal zirconia polycrystals subjected to grinding. Journal of the mechanical behavior of biomedical materials. 2019;93:222-9. [33] Fiocchi AA, de Angelo Sanchez LE, Lisboa-Filho PN, Fortulan CA. The ultraprecision Ud-lap grinding of flat advanced ceramics. Journal of Materials Processing Technology. 2016;231:336-56. 
[34] Denkena B, Köhler J, Turger A, Helmecke P, Correa T, Hurschler C. Manufacturing conditioned wear of all-ceramic knee prostheses. Procedia CIRP. 2013;5:179-84.

[35] Li Z, Zhang F, Luo X, Chang W, Cai Y, Zhong W, et al. Material removal mechanism of laser-assisted grinding of RB-SiC ceramics and process optimization. Journal of the European Ceramic Society. 2019;39:705-17.

[36] Lu A, Jin T, Liu Q, Guo Z, Qu M, Luo H, et al. Modeling and prediction of surface topography and surface roughness in dual-axis wheel polishing of optical glass. International Journal of Machine Tools and Manufacture. 2019;137:13-29.

[37] Zeng Q, Qin Y, Chang W, Luo X. Correlating and evaluating the functionalityrelated properties with surface texture parameters and specific characteristics of machined components. International Journal of Mechanical Sciences. 2018;149:62-72. [38] Wang Q, Cong W, Pei Z, Gao H, Kang R. Rotary ultrasonic machining of potassium dihydrogen phosphate (KDP) crystal: An experimental investigation on surface roughness. Journal of Manufacturing Processes. 2009;11:66-73.

[39] Huh YH, Park CJ, Cho LR. Evaluation of various polishing systems and the phase transformation of monolithic zirconia. J Prosthet Dent. 2016;116:440-9.

[40] Pan R, Zhong B, Chen D, Wang Z, Fan J, Zhang C, et al. Modification of tool influence function of bonnet polishing based on interfacial friction coefficient. International Journal of Machine Tools and Manufacture. 2018;124:43-52.

[41] Lu A, Jin T, Guo Z, Qu M, Chang Y, Liu Q, et al. Characterization of the tool influence function in a dual-axis wheel polishing process to achieve high material 
removal rates. Precision Engineering. 2018;52:276-90.

[42] Chen F, Hao S, Miao X, Yin S, Huang S. Numerical and experimental study on low-pressure abrasive flow polishing of rectangular microgroove. Powder technology. $2018 ; 327: 215-22$.

[43] Chen F, Wang H, Tang Y, Yin S, Huang S, Zhang G. Novel cavitation fluid jet polishing process based on negative pressure effects. Ultrasonics sonochemistry. 2018;42:339-46.

[44] Roy T, Choudhury D, Mamat AB, Pingguan-Murphy B. Fabrication and characterization of micro-dimple array on $\mathrm{A} 12 \mathrm{O} 3$ surfaces by using a micro-tooling. Ceramics International. 2014;40:2381-8.

[45] Luo J. Integrated Modeling of Chemical Mechanical Planarization/Polishing (CMP) for Integrated Circuit Fabrication: From Particle Scale to Die and Wafter Scales: University of California, Berkeley, 2003.

[46] Zeng S, Blunt L. Experimental investigation and analytical modelling of the effects of process parameters on material removal rate for bonnet polishing of cobalt chrome alloy. Precision Engineering. 2014;38:348-55.

[47] Liao W, Nie X, Liu Z, Nie X, Wan W. Researches on formation mechanism of ultra-smooth surface during ion beam sputtering of fused silica. Optik. 2019;179:95764.

[48] Chia C, Jeffrey SS, Howe RT. Scalable methods for ultra-smooth platinum in nanoscale devices. Micro and Nano Engineering. 2019;3:50-8.

[49] Zhou Y, Pan G, Shi X, Zhang S, Gong H, Luo G. Effects of ultra-smooth surface 
atomic step morphology on chemical mechanical polishing (CMP) performances of sapphire and SiC wafers. Tribology international. 2015;87:145-50.

[50] Zhong-yu P, Dong-hui W, Lin-zhi Y, Meng-meng Z. Ultra-smooth $\mathrm{Cu}$ surface fabricated by hydrodynamic suspension polishing technique. Precision Engineering. 2019;57:189-94.

[51] Li HN, Yang Y, Zhao YJ, Zhang Z, Zhu W, Wang W, et al. On the periodicity of fixed-abrasive planetary lapping based on a generic model. Journal of Manufacturing Processes. 2019;44:271-87.

[52] Peng W, Guan C, Li S. Surface evaluation and evolution during hydrodynamic effect polishing for quartz glass. Applied optics. 2014;53:6913-9.

[53] Klocke F, Dambon O, Bletek T, Höche T, Naumann F, Hutzler T. Surface Integrity in Ultra-Precision Grinding of Transparent Ceramics. Procedia CIRP. 2018;71:177-80. [54] Santos R, Buciumeanu M, Silva F, Souza J, Nascimento R, Motta F, et al. Tribological behavior of zirconia-reinforced glass-ceramic composites in artificial saliva. Tribology International. 2016;103:379-87. 